\title{
EJA: A Formação Docente e seus Desafios na Preparação do Aluno para o Mundo Moderno
}

\author{
CRUZ, Antonio Carlos dos Santos ${ }^{[1]}$
}

CRUZ, Antonio Carlos dos Santos. EJA: A Formação Docente e seus Desafios na Preparação do Aluno para o Mundo Moderno. Revista Científica Multidisciplinar Núcleo do Conhecimento. Ano 03, Ed. 03, Vol. 01, pp 5-17, Março 2018. ISSN: 2448-0959

\section{RESUMO}

O presente artigo pretende analisar a contribuição do papel do professor, da evolução da EJA e dos diversos saberes docentes habilidades para que tragam a consolidação da modalidade de ensino na educação formal e desencadeiam enumeras reflexões pedagógicas redimensionamento da Educação de Jovens e Adultos. A formação de professores para a EJA é essencial para que haja uma educação de qualidade, pois somente desta maneira o educador será capaz de elaborar didáticas que resultem bons desempenhos em sala de aula, garantindo a permanência desses alunos na escola. Mostrando-os a importância de continuar seus estudos, a fim de que se tornem cidadãos críticos e reflexivos para que possam interagir de forma participativa na sociedade.

Palavras-Chave: Educação, Jovens e Adultos, Formação, Professores, Práxis.

\section{INTRODUÇÃO}

O desenvolvimento da alfabetização de adultos no Brasil acompanha a História da Educação como um todo e teve início com o trabalho de catequização e ensino das primeiras letras, realizado pelos jesuítas, durante o Brasil colônia.

Ao longo do tempo, o avanço econômico e tecnológico passou a exigir mão-de-obra cada vez mais qualificada e alfabetizada, com isso várias medidas políticas e pedagógicas foram sendo adotadas, tais como: a Campanha de Educação de Adolescentes e Adultos (CEAA), a Campanha Nacional de Erradicação do Analfabetismo (CNEA), o Movimento MOBRAL, o Ensino Supletivo etc.

A formação de jovens e adultos começou, quando se viu necessário profissionalizar a nova sociedade pós- 
escravidão, para a recente industrialização e urbanização do país.

Deste período até os dias de hoje muito se foi feito para que a Educação de Jovens e Adultos fosse vista não apenas como uma forma de habilitação para o mercado de trabalho, mas como a formação de cidadãos críticos, reflexivos e autônomos.

Delimitou-se como objetivo geral analisar as contribuições para a reflexão sobre o papel do professor, a evolução da EJA e os diversos saberes docentes habilidades para que tragam a consolidação da modalidade de ensino na educação formal e desencadeiam enumeras reflexões pedagógicas redimensionamento da Educação de Jovens e Adultos.

A justificativa do estudo está no fato de mostrar que o papel do professor é de mediador desta formação, utilizando métodos de ensino adequados, possibilitando aos alunos a oportunidade de alcançarem cada vez mais um novo nível de conhecimento que satisfaça suas necessidades como individuo de uma sociedade. Para que esse objetivo seja alcançado têm-se a preocupação com a formação do professor, que deve ser contínua.

A formação de professores voltada à EJA visa aperfeiçoar técnicas pedagógicas, metodologias de ensino que possibilitem a permanência desses educandos na escola, proporcionando-lhes um ensino significativo, que os levem à análise crítica dos fatos abordados em sala de aula e do seu meio social.

Como metodologia utilizou-se da pesquisa bibliográfica, no qual utilizou-se da revisão de literatura, onde foram pesquisas livros, artigos e sites da internet que tratam da questão da EJA e sua importância social.

\section{EDUCAÇÃO DE JOVENS E ADULTOS (EJA) NO BRASIL}

\subsection{EJA NO BRASIL}

Com a chegada dos padres jesuítas, vindos nas embarcações dos colonizadores portugueses, se deu o início do processo de educação no Brasil. O sistema jesuítico de ensino foi implantado como uma das formas de dominar os nativos,

Tratava-se da aculturação sistemática dos nativos, educação que perdurou por volta de duzentos e dez anos, e que não relegou suas funções como dominadores espirituais, ancorou a sua linha curricular de forma muito competente, fazendo maciço investimento na erudição de seus alunos com o apoio a realeza. (GENTIL, 2005, p. 2).

O fim deste sistema de ensino se deu, quando a coroa portuguesa percebeu que o domínio dos jesuítas tinha crescido com o passar do tempo. Contudo, a realeza não se preocupou em manter uma educação de qualidade para os adultos da colônia. Posteriormente, com a chegada da realeza ao Brasil em 1808, constatou-se a necessidade de formar uma nova sociedade que atendesse ao processo de urbanização e industrialização.

No desenvolvimento da sociedade, que começou a ser industrial e urbana, surgiu a necessidade de se ter certo domínio de conhecimento e que se apresentasse algumas habilidades de trabalho, de modo que a escola passou a assumir a função de educar para a vida e para a aprendizagem do trabalho. (GENTIL, 
2005, p. 3).

Segundo Gentil (2005, p.03), "no ano de 1854 surgiu a primeira escola noturna e em 1876 já existiam 117 escolas por todo o país". Desde período em diante o termo Educação para Jovens e Adultos se tornou mais comum dentro do parlamento. Já no início do século XX, especialmente na década de 30, as discussões sobre a EJA levaram à inclusão na Constituição de 1934 a gratuidade do ensino e frequência obrigatória dos alunos, incluindo os adultos.

A década de 40 pode ser considerada marcante para a educação de jovens e adultos, visto que houve várias iniciativas políticas e pedagógicas com esse propósito, tais como: regulamentação do FNEP (FUNDO NACIONAL DE ENSINO PRIMÁRIO), criação do INEP, primeiras atividades voltadas ao supletivo, lançamento da CEAA (CAMPANHA DE EDUCAÇÃO DE ADOLESCENTES E ADULTOS), $1^{\circ}$ Congresso Nacional de Educação de Adultos em 1947 e o Seminário de Interamericano de Educação de Adultos em 1949.

$\mathrm{Na}$ década de 50, devido o crescimento das indústrias, foi preciso formar pessoas qualificadas para o trabalho. Porém, no fim dessa década e meados da década de 60 pode-se dizer que a preocupação com a educação de adultos ampliou, levando ao II Congresso Nacional de Adultos, contando com a participação de Paulo Freire que propôs uma educação de adultos que os possibilitassem a interagir com o meio social e político.

O que chamou a atenção dos educadores e políticos da época foi o fato de que o método Paulo Freire "acelerava" o processo de alfabetização de adultos. Paulo Freire não estava aplicando ao adulto alfabetizando o mesmo método às crianças (GADOTTI, 2006, p. 50).

Com isso o método de Freire serviu de inspiração para vários movimentos no campo da educação popular. Contudo, no período do golpe militar Paulo Freire foi exilado e suas propostas "engavetadas".

A coragem de pôr em prática um autêntico trabalho de educação que identifica a alfabetização com um processo de conscientização, capacitando o oprimido tanto para a aquisição dos instrumentos de leitura e escrita quanto para a sua libertação, fez dele um dos primeiros brasileiros a ser exilados (GADOTTI, 2006, p. 43).

Neste período a EJA sofreu uma estagnação, pouco se fez. Com a volta da Democracia e com a criação da Constituição Federal de 1988, a EJA ganhou novos alicerces baseados no artigo 208.

O dever do Estado com a educação será efetivado mediante a garantia de: I - ensino fundamental obrigatório e gratuito, assegurado, inclusive sua oferta gratuita para todos os que a ele não tiveram acesso na idade própria (CONSTITUIÇÃO FEDERAL, 1988, apud GENTIL, 2005, p. 6).

A partir da Constituição de 1988, a educação de jovens e adultos, em forma de supletivo, passou a ser um direito público, sendo-lhe ofertada obrigatoriamente. Na década de 1990, esta temática passou a ser mais discutida, tendo a educação da população como ferramenta para o desenvolvimento do país. Alfabetizar os adultos e incentivá-los a continuar os estudos é uma forma de garantir o direito à liberdade de expressão e comunicação na sociedade, de forma igualitária, onde todos, sem restrições, possam sentir-se de fato cidadãos interagindo com o meio. Por esse motivo, há uma preocupação com a qualificação de 
profissionais para desempenhar essa tarefa árdua.

Cabe ao professor, estimular esses alunos a reconhecerem na educação a ponte para a liberdade, para seu desenvolvimento intelectual perante a sociedade. $\mathrm{O}$ educador deve obter recursos didáticos adequados à realidade desses educandos, utilizando sua práxis, que para Paulo Freire era entendida como "ação + reflexão" (GADOTTI, 2006, p.48). Disparidades entre a Teoria e a Prática

Durante a formação do futuro professor existem disciplinas voltadas apenas às práticas pedagógicas. Aprende AS teorias, estudam os filósofos, os pensadores. No entanto, na maioria das vezes, devido à realidade dessa clientela, nem sempre é possível fazer essa relação e é de grande dificuldade aplicar essas teorias à prática. Analisando, percebe-se que o professor, na prática, não consegue utilizar os conhecimentos estudados sobre os pensadores da educação e sobre os filósofos por achar que é inadequado com a situação que ele encontra no ensino da EJA.

O problema é a sensibilidade que o professor deve ter é observar sempre quem é esse aluno, onde ele está e quais são os seus objetivos, esse professor deve estar atualizado, levando sim, em que situações deve seguir a risca o que foi aprendido na vida acadêmica. A teoria e a prática devem estar paralelas no ensino/aprendizagem buscando novas metodologias aplicáveis em sala de aula e aos alunos da EJA.

Há décadas, entendem- se a necessidade de novos métodos e práticas que sejam específicas para o ensino de jovens e adultos. Segundo Paulo Freire (1979) o professor é apenas um ajustador do aluno em relação à alfabetização (aprendizagem), o aluno é quem deve criar o saber, criar no sentido de fazer a alfabetização de dentro pra fora. Esse saber não tem de ser entendido como algo que é posto ou doado pelo professor ao aluno.

Em razão desse pensamento procura-se método capaz de fazer instrumentos tanto do professor quanto do aluno e que identifique o conteúdo da aprendizagem com o processo de aprendizagem, ou seja, o conteúdo quando relacionado com a realidade do mesmo oferece aprendizagem que faça sentido, muito mais que saber engessado como os das cartilhas que fazem o analfabeto mais à condição de objeto do que de sujeito.

Outro problema visto na realidade é o uso de materiais didáticos e metodologias inadequadas que vem se arrastando desde muito tempo e isso aliena o aluno. O melhor método é utilizar o próprio aluno, sua capacidade de pensar e refletir, interagir, uma vez que se acredita que ele é autor de sua própria história, de fazê-lo acreditar em seu potencial, empoderá-lo e que ele mesmo acredite nisso, para que ele entenda a sua função social no lugar e no tempo. Ou seja, o professor aproveitar os conhecimentos em sala de aula deixar a aula contextualizada.

O conhecimento que o educando traz de fora da sala de aula é mais importante para o seu aprendizado quando relacionado com o conteúdo de modo a torná-lo crítico e reflexivo na sociedade, considerando tanto sua comunidade em sua volta quanto o mundo como um todo.

Que a educação seja o processo através do qual o indivíduo toma a história em suas próprias mãos, a fim de mudar o rumo da mesma. Como? Acreditando no em si mesmo e em sua capacidade de transformação, na sua capacidade de aprender, descobrir, criar soluções, desafiar, enfrentar, propor, escolher e assumir as consequências de sua escolha. Mas isso não será possível se continuarmos bitolando os alfabetizando com 
desenhos pré-formulados para colorir, com textos criados por outros para copiarem, com caminhos pontilhados para seguir, com histórias que alienam, com métodos que não levam em conta a lógica de quem aprende. (FUCK, p. 14 e 15, 1994).

\subsection{O PERFIL DOS ALUNOS DA EJA}

É preciso que a todos, inclusive a escola compreendam que os educandos de Educação de Jovens e Adultos vivem problemas como preconceito, vergonha, discriminação, críticas, dentre tantos outros e que tais questões são vivenciadas tanto no cotidiano familiar como na vida em comunidade. Os alunos de Educação de Jovens e Adultos têm um traço de vida, origens, idade, vivências profissionais, históricos escolares, ritmos de aprendizagem e estruturas de pensamentos muito diferentes.

São pessoas que vivem no mundo do trabalho, capitalismo, com responsabilidades sociais e familiares, com valores éticos e morais formados a partir da experiência, do ambiente e da realidade cultural em que estão inseridos e nada disso deve ser relevado no processo educacional. Arroyo assim afirma, essas diferenças podem ser uma riqueza para fazê-lo educativo.

Quando os interlocutores falam de coisas diferentes, o diálogo possível. Quando só os mestres têm o que falar não passa de um monólogo. Os jovens e adultos carregam as condições de pensar sua educação como diálogo. Se toda educação exige uma deferência pelos interlocutores, mestres e alunos (as), quando esses interlocutores são jovens e adultos carregados de tensas vivências, essa deferência deverá ter um significado educativo especial. (ARROYO, 2006, p. 35).

São dois os conhecimentos que se dividem em um indivíduo são divididos em dois: o pré-estabelecido e o saber adquirido. O primeiro, quer dizer aquele saber da primeira relação com o mundo e fundado na percepção das coisas e do outro, de acordo com suas experiências e vivências, o famoso conhecimento prévio. Já o segundo, é o saber adquirido dentro da sala de aula, teorias, ensinamentos, e ambos são importantes para sua formação onde nenhum pode ser dispensado.

O ambiente escolar, para ser satisfatório, tem que ser transformado para o acolhimento dos alunos, que é alguém especialmente receptivo à aprendizagem, repleto de curiosidades e que vai para a sala de aula desejoso de novas experiências, como por 3 exemplo, aulas interativas, criativas, reflexivas, fáceis e participativas.

Depois disso, o principal não é a matrícula desse aluno, mas sim, a permanência desse jovem e adulto na escola, para que produzam conhecimentos e se tornem sujeitos mais ativos, participativos e cresçam cultural, social e economicamente no meio social em que vivem. Ao escolherem o caminho da escola, os jovens e os adultos optam por uma via propícia para promover o seu desenvolvimento pessoal.

Trata-se de uma decisão que envolve as famílias, os patrões, as condições de acesso e as distâncias entre a casa e a escola, as possibilidades de custear os estudos e, muitas vezes, trata-se de um processo contínuo de idas e vindas, de ingressos e desistências. Ir à escola, para um jovem ou adulto, é, antes de tudo, um desafio, um projeto de vida.

Uma característica frequente dos alunos é sua baixa auto-estima, muitas vezes reforçada pelas situações de fracasso escolar. A sua eventual passagem pela escola, muitas vezes foi marcada pela exclusão e/ou 
pelo insucesso escolar. Esse fracasso escolar tem também outros pontos importantes, por exemplo, forma como o aluno interage com o ambiente escolar, modo como estabelece relações com o saber e com o aprender, seu relacionamento com os professores e com colegas, suas relações familiares e os vínculos que constrói com o conhecimento.

Em relação à escola, os motivos são o modelo pedagógico, perfil dos professores, falta de material, dentre outros. No âmbito social, o fracasso fica por conta das políticas públicas de educação e a secular desigualdade econômica e social da sociedade brasileira. Para uma pessoa adulta que retoma seus estudos, o desejo maior é o de se preparar para o trabalho, de ter autonomia e de se dar bem profissionalmente.

A abordagem metodológica neste sentido não deve ser desenvolvida com os mesmos parâmetros utilizados para se trabalhar com crianças. Um aluno com idade de 30 anos, por exemplo, retomando os anos escolares correspondente ao $4^{\circ}$ ano do ensino fundamental não se interessará por uma atividade caracterizadamente infantil. Daí a necessidade de abordar conteúdos equivalentes, mas com uma linguagem adulta e que vá ao encontro daquilo que esse público deseja.

A educação é o maior e melhor instrumento gestor de mudança, através dela o homem consegue compreender melhor a si mesmo e ao mundo em que vive, dessa forma, a própria educação deve ser a primeira a aceitar e a acompanhar o desenvolvimento e suas especificidades, ou seja, renovar e promover a interação com o novo, ou tornar essa clientela apta ao trabalho e enfrentamento dos desafios sociais, com participação igualitária.

O Brasil já deu um grande passo nas questões que se referem a alfabetização de jovens e adultos, embora continuamos dentro da escola dos países com maior taxa de analfabetos. E o problema, como já mencionado, é que o adulto que procura a escola não quer apenas aprender a ler e a escrever, ele quer e necessita é de atualização com o contexto social em que vive e faz parte.

A defasagem escolar é grande, segundo a Lei 9.394/96 art. 37 “a educação de jovens e adultos deverá articular-se, preferencialmente, com a educação profissional, na forma do regulamento", dessa forma, e se realmente acontecesse o que está previsto em lei, teríamos muito mais jovens dentro das escolas. Em consequência do desemprego, a busca pelo ensino profissional e técnico aumentou significativamente. $\mathrm{O}$ jovem quer trabalhar, mas falta qualificação e oportunidades, principalmente a de concluir a educação básica e ter parcial domínio das novas tecnologias.

\subsection{FORMAÇÃO DOCENTE E A SUA PRÁTICA PEDAGÓGICA}

O perfil dos professores se constitui ao longo de sua carreira e necessita de acompanhamento em longo prazo. Ou por todo o tempo "Em termos de grupo, o perfil consubstancia-se historicamente na cultura profissional, como patrimônio que assegura a sobrevivência do grupo e permite a definição de estratégias indenitárias adaptadas a cada realidade histórica social" (ESTRELA, 1997, p.47). Ser professor significa contribuir para a formação de cidadania, portanto, o docente faz toda a diferença:

Com muita frequência ouve-se entre os profissionais da educação, das diversas modalidades de ensino que é necessário valorizar/ potencializar/ aproveitar nos educandos, os "saberes cotidianos, os conhecimentos que trazem de casa, as experiências vivenciadas" e/ou outras expressões que nos remetem a esta habitual fala que se tornou comum nas instituições escolares, e quando se fala em Educação de 
Jovens e Adultos estas falas são ainda mais contundentes.

Para Freire (1988, p. 80), a "leitura do mundo precede a leitura da palavra", isso nos indica que os "saberes" que estão atualmente nos textos escritos da nossa sociedade, nem sempre estiveram ali, e que, não surgiram por acaso. Ao contrário, tais saberes são fruto de sangue e suor, construídos historicamente pela cultura, implicando em lutas sociais na sua produção.

A figura do professor poderia simbolicamente ser comparada com a de um maestro criativo que exigiria dos componentes da orquestra: organização, iniciativa própria, envolvimento, dedicação e, principalmente, ações coletivas desencadeadas por processos participativos. "Sendo criativo, articulador, mediador e desafiador, o professor apostaria em todos os meios e recursos existentes para consolidar a construção do conhecimento" (BEHRENS, 1996, p. 64).

As constantes transformações nas áreas econômica, política e social, tecnológica e cultural da sociedade atual, têm pressionado a escola a se adequar conforme as exigências do mundo do trabalho, influenciando a educação. Decorrentes a essas mudanças surgem novos desafios, no final do século XX, a escolarização passa a ser exigida no mundo do trabalho, assim aumenta a demanda da educação de jovens e adultos na sociedade.

A Lei n. 9394/96 (BRASIL, 1996), em seu artigo 38, determina que, no nível de conclusão do Ensino Fundamental e Médio, a idade seja, 15 e 18 anos. E de acordo com a Deliberação n. 088/00,do CEE-PR, o ingresso na EJA pode se dar aos 14 anos para o Ensino Fundamental e aos 17 para o Ensino Médio.

Esta faixa etária exige várias alterações frente a essas mudanças, passa a exigir também um ensino voltado para o campo da pesquisa e ao trabalho criativo. Com relação à qualidade da formação para atuação na EJA, o que ocorre é uma crescente descaracterização dos cursos de formação, juntamente a falta de livros escritos que propicie apoio a essa formação, a pouca contribuição das universidades, ao desprezo desde ensino e a formação para o trabalho docente.

São muitos os desafios o que torna a prática de ensinar cada vez mais complexa para superar uma formação fragmentada, tanto a instituição formadora de professores como os formadores e os futuros professores, precisam assumir que na, sociedade globalizada? se convive, simultaneamente, com a inovação e a incerteza. Por isso, a educação dos seres humanos se torna mais complexa, e a formação do professor, também, passa a assumir essa complexidade.

Para superar a dicotomia entre ensino e pesquisa, teoria e prática, e possibilitar a construção de uma práxis dinamizada pela iniciativa, pelo envolvimento do futuro professor em projetos educativos próprios e fundamentados, torna-se necessário reconhecer tal complexidade (2006, p.12-13).

A concepção moderna do educador exige uma sólida formação cientifica, técnica e política, claro que, atrelada a uma prática pedagógica crítica e consciente para avaliar a atual condição da educação.

Dessa forma, faz-se necessário uma qualificação dos profissionais envolvidos neste processo, é fundamental que a equipe docente esteja bem preparada, por este motivo é extremamente importante uma formação continuada, onde todos tenham a oportunidade de repensar a sua prática. Pois, a formação continuada é um processo possível para a melhoria da qualidade do ensino, dentro do contexto 
educacional contemporâneo.

A formação continuada pode ser caracterizada como uma tentativa de resgatar a figura do mestre, tão carente do respeito devido a sua profissão, tão desgastada em nossos dias. "Ninguém nasce educador ou marcado para ser educador. A gente se faz educador, a gente se forma, como educador, permanentemente, na prática e na reflexão da prática". (FREIRE, 1997, 58).

Para o autor, formação permanente é uma conquista da maturidade, da consciência do ser. Quando a reflexão permear a prática, docente e de vida, a formação continuada será exigência para fazer do homem atuante no seu espaço histórico, crescendo no saber e na responsabilidade.

A prática educativa é acima de tudo um desafio, pois o educador consciente passa grande parte do seu tempo questionando-se, revendo conceitos, buscando dar o melhor a seus educandos. Por isso, o sonho e a utopia fazem parte desses docentes, e outros sentimentos como a esperança, que é uma arma importantíssima para a realização de certas aspirações. Para Paulo Freire (1997) é ingenuidade dar à esperança um poder absoluto de resolução de conceitos, concepções e conteúdo, no entanto, se aliadas a ela encontram-se o esforço, a capacidade, a persistência e humildade, o educador está no caminho certo.

A formação de professores no Brasil, historicamente, tem forte influência das chamadas escolas normais, que foram o lócus da formação de professores até o período da Reforma Universitária de 1968, quando da criação das faculdades de educação.

O resultado das reformas da ditadura militar foi a convivência entre um $2^{\circ}$ grau técnico em magistério, que prepararia os professores para os anos iniciais do $1^{\circ}$ grau e as licenciaturas curta e plena, nas universidades, que titulariam os professores das diversas disciplinas de $5^{\mathrm{a}}$ a $8^{\mathrm{a}}$ séries do $1^{\mathrm{o}}$ grau e os professores das diversas disciplinas do $2^{\circ}$ grau.

Esse modelo de formação de professores que vigorou até a LDB/96, em seu formato padrão não previa formação específica para atender os alunos jovens e adultos. A exceção à regra de não formação específica para EJA teve início no final da década de 1980, quando as faculdades de educação realizaram amplo debate sobre a atuação do pedagogo e sua habilitação profissional.

Resulta desse rico debate a compreensão, assumida principalmente pelas instituições públicas de educação superior, de que os pedagogos deveriam ser habilitados prioritariamente como professores, podendo atuar na gestão pública da educação em diversos campos, como diretor, coordenador, supervisor, mas de que sua matriz de formação era de fato o magistério dos anos iniciais do $1^{\circ}$ grau. A partir dessa compreensão, alguns cursos de pedagogia, pelo País, passam a ter ênfases específicas em sua habilitação. Dessa experiência resultam os cursos de pedagogia, com ênfase ou habilitação em EJA.

\section{CONSIDERAÇÕES FINAIS}

A educação de adultos, dentro desse contexto, torna-se mais que um direito: é a chave para o século XXI; é tanto conseqüência do exercício da cidadania como condição para uma plena participação na sociedade. Além do mais, é um poderoso argumento em favor do desenvolvimento ecológico sustentável, da democracia, da justiça, da igualdade entre os sexos, do desenvolvimento socioeconômico e científico, além de ser um requisito fundamental para a construção de um mundo onde a violência cede lugar ao 
diálogo e à cultura de paz baseada na justiça.

Os esforços brasileiros atuais, em especial o Programa Brasil Alfabetizado, de 2003, são os maiores que o Brasil já fez para erradicação do analfabetismo. Esses esforços entretanto, seriam apenas letra morta, caso não houvesse a participação da sociedade civil. É graças a entidades como a Associação Alfabetização Solidária - que esse e outros programas de interesse para nossa sociedade conseguem ser implementados. Fundada há 11 anos, a ALFASOL tem se destacado como um modelo nacional em Educação de Jovens e Adultos.

Essa modalidade de ensino pode e deve ser estendida, do ponto de vista metodológico, a outras modalidades existentes. No que diz respeito principalmente ao aproveitamento da "história de vida" de seus participantes e, em seu uso no processo de aprendizagem, a EJA demonstra sucessos semelhantes aos obtidos nos processos de ensino aprendizagem. É notório que o conhecimento humano é uma escada construída sobre os degraus colocados por nossos antepassados étnicos e/ou culturais. O homem não precisa reinventar a roda a cada geração. Mas pode melhorá-la.

Um dos maiores problemas enfrentados pelos estudantes, e eu me coloco nesse meio quando recordo as dificuldades iniciais com números e outros conceitos um tanto quanto abstratos, é que a capacidade de exemplificação de cada professor era o que nos fazia aprender ou não os conceitos dados. Foi a partir de meus estudos sobre a história grega, que conceitos como o dos teoremas clássicos ficaram mais claros.

O fato de saber como viviam e como pensavam, proporcionou-me um maior entendimento sobre seus cálculos, que eram uma incógnita à época em que os aprendi, pois não lhes conhecia a utilidade. Da mesma forma, um professor que não domina os conceitos culturais de seus alunos, não consegue, na maior parte das vezes, fazer-se entender a contento. Não porque os alunos sejam ignorantes, longe disso, mas simplesmente porque sua realidade cultural é tão diferente da do professor, que os dois não conseguem falar a mesma língua, mesmo ela sendo o português. São os assim chamados ruídos da comunicação.

Nas palavras de Ubiratan D’Ambrosio, professor dos programas de Pós-Graduação em História da Ciência e em Educação Matemática da PUC de São Paulo: "o Brasil destacou-se juntamente com os Estados Unidos, pelo potencial da etno matemática na educação.

Em sintonia com o pensamento de Paulo Freire, ela demonstrou que, além da importante pesquisa sobre o saber e o fazer matemático de várias culturas, abordado nas dimensões etnográfica, histórica e epistemológica da etno matemática, dá-se igual importância à dimensão pedagógica, uma vez que ela propõe uma alternativa à educação tradicional (2005, p. 9).

"A idéia, portanto, não é de desprezar o saber acadêmico tradicional, mas sim de, complementá-lo quando necessário, com uma abordagem etnológica, a fim de aproveitar os conhecimentos dos alunos como feedback para a reestruturação do conceito pedagógico utilizado.

Dessa forma, a EJA, além de ser um modelo pedagógico indispensável para vencer o desafio do analfabetismo brasileiro de uma vez por todas, também pode ser considerada uma metodologia base para a formação de alunos e professores para os níveis elementar e médio. Dessa forma, esses docentes poderão entender melhor e vencer as barreiras de aprendizagem de seus alunos. Afinal, o que se deseja é 
que as pessoas aprendam a aprender. Só assim o conhecimento poderá ser multiplicado e plenamente utilizado. Isso vem diretamente ao encontro do interesse nacional em aumentar a produtividade e a competitividade do país ao nível internacional.

\section{REFERÊNCIAS}

ARROYO, M. Educação de Jovens e Adultos: um campo de direitos e de responsabilidade pública. In: GIOVANETTI, Maria Amélia, GOMES, Nilma Lino e SOARES, Leôncio (Orgs.). Diálogos na Educação de Jovens e Adultos. Belo Horizonte, MG: Autêntica, 2006, p.19-50.

BARDHAN, Pranab. A Globalização é Boa ou Ruim para os Pobres? Scientific American Brasil nº 48. São Paulo: Duetto Editorial. Maio de 2006.

CAPRA, Fritjof. O Ponto de Mutação. São Paulo: Cultrix, 1995.

Cohen, David. Equilíbrio Distante - Exame / A Empresa do Novo Milênio. São Paulo: Abril, 2000.

CONFINTEA. Declaração de Hamburgo - Agenda para o Futuro. Brasília: SESI/UNESCO, 1999.

D’AMBROSIO, Ubiratan. Volta ao Mundo em 80 Matemáticas. Scientific American Brasil. Edição Especial n 11. São Paulo: Duetto Editorial. 2005.

Dantas, Fernando. Brasil Busca Receita de Crescimento. O Estado de São Paulo. 21 de maio de 2006.

Taxa de analfabetismo reduz ritmo de queda no governo Lula. O Estado de São Paulo. 17 de setembro de 2006.

DRUCKER, Peter. Sociedade Pós-Capitalista. São Paulo: Pioneira, 1999.

Malthus, Thomas Robert. Ensaio Sobre a População - Os Economistas. São Paulo: Nova Cultural, 1996.

SANDRONI, Paulo. Dicionário de Economia e Administração. São Paulo: Nova Cultural, 1996.

SANTOS, Fábio. Entrevista com o cientista político Alberto Carlos Almeida. Destak. 10 de setembro de 2007. Fontes na Internet

OIT / KILM - http://www.ilo.org/public/english/employment/strat/kilm/index.htm. OIT, 2005.

ISO 14000 - Gestão Ambiental. www.cnpma.embrapa.br. ISO, 2000.

MARTINS, A. B; COSTA, C. S; LEITE, S. F. Desafios da Formação de Professores da Educação de Jovens e Adultos. Revista Educação em Destaque. Vol. 01, nº 01, abril de 2008, Disponível em: http://www.cmjf.com.br/revista/materiais/1209993852.pdf. Acesso em: 16/12/2011.

OLIVEIRA, R. P; ARAÚJO, G. C. Qualidade do ensino: uma dimensão da luta pelo direito à educação. Revista Brasileira de Educação, n. 28, p. 5-23, jan./fev./ mar./ abr. 2005. PAIVA, J; MACHADO, M. M; IRELAND, T. (Orgs.). Educação de Jovens e Adultos: uma memória contemporânea. Brasília: MEC, 2004.

RIBEIRO, V. M. (org.) Educação de jovens e adultos: novos leitores, novas leituras. Campinas: 
Mercado de Letras/ALB, 2001. SAVIANI, D. O Plano de Desenvolvimento da Educação: análise do projeto do MEC.

11 Doctorado em Ciencias de la Educación de Universidad Autónoma de Asunción (UAA).

PUBLIQUE SEU ARTIGO CIENTÍFICO EM:

https://www.nucleodoconhecimento.com.br/enviar-artigo-cientifico-para-submissao 